\title{
Aplikasi Informasi Harga Material Bangunan Berbasis Android
}

\author{
Rian Tarsis Tjioetama, Sherwin R.U.A. Sompie, Xaverius B.N. Najoan \\ Teknik Informatika Universitas Sam Ratulangi Manado, Indonesia. \\ tjiofang@gmail.com, aldo@unsrat.ac.id, xnajoan@unsrat.ac.id
}

\begin{abstract}
Manado adalah salah satu ibukota yang terletak di profinsi Sulawesi utara yang sedang berkembang, setiap tahun angka pembangunan di kota Manado semakin meningkat seiring dengan perkembangan jaman. Tingginya angka pembangunan di Manado menjadi kesempatan bagi pelaku usaha toko bangunan di kota Manado untuk mejual berbagai bahan dasar bangunan yang mereka jual, seiring dengan perkembangan jaman maka di butuhkan media informasi untuk mempermudah mengakses informasi harga material yang ada maka melalu permasalahan itu di buatlah Aplikasi Informasi Daftar Harga Material Bangunan Bebasis Android untuk mepermuda dalam mengakses informasi harga material bangunan di kota Manado.

Kata Kunci : Aplikasi, Android, Material Bangunan, Manado, Sistem Informasi
\end{abstract}

Manado is one of the capitals located in the developing province of north Sulawesi, evry year the number of developments in the city of Manado is increasing along whit the times. The high number of development in Manado is an opportunity for business people in the bulding shop in Manado to sell various basic bulding materials they sell, along whit the times information media is needed to make it easier to access the material price information, then through the information application. Price list of Android-based bulding Materials for young people in accessing information on building material price in the city of Manado

Keywords: Application, Android, Building Material, Manado, Information Systems.

\section{PENDAHULUAN}

Perkembangan Teknologi yang terus bergerak maju mendorong masyarakat untuk terus mengikuti perkembangan tersebut. Banyak hal yang ditawarkan dari kemajuan teknlogi yang sangat pesat. Sehubungan dengan semakin berkembangnya Teknologi dan Informasi sekarang ini kebutuhan masyarakat juga ikut bertambah salah satunya dalam berbagai pembanguna. Tujuan dari pembangunan itu sendiri yaitu untuk menciptakan kemajuan dalam berbagai bidang, yang bisa dikatakan bahwa teknologi dan pembangunan saling membutuhkan. Sekarang ini Indonesia adalah salah satu negara dengan angka pembangunan yang sedang meningkat setiap tahun. Ada begitu banyak pembangunan infrastruktur yang merupakan pembangunan nasional yang dilakukan untuk mewujudkan wilayah yang teratur dan sementara di bangun oleh pemerintah pusat baik di perkotaan besar, menengah, kecil, bahkan sampai ke pelosok desa. Tingginya angka pembangunan di Indonesia berdampak pada setiap pelaku usaha dalam setiap kalangan yang salah satunya adalah toko bangunan, oleh karna itu di perlukan juga terobosan baru oleh pelaku usaha toko bangunan untuk mengikuti perkembangan teknologi yang sedang berkembang di era sekarang ini karena pada dasarnya hamper segala usia menuntut sesuatu yang praktis dan lebih mudah.

Di dalam Masyarakat yang mengikuti perkembangan zaman, tentunya di hadapkan dengan berbagai permasalahan dalam segala aspek termasuk pembangunan. Permasalahan yang sering muncul seirirng dengan perkembangan zaman sekarang ini di kalangan masyarakat, perusahaan ataupun usaha kecil yng ingin berkembang dalam segi infrastruktur adalah kurangnya informasi tentang harga material bangunan pdahal banyak pembangunan saat ini di tuntut untuk cepat selesai seperti salah satu contoh yaitu sebuah café, mereka di tuntut untuk mengikuti persaingan bisnis apalagi sekarang ini kebnyakan masyarakat yang paling besar adalah generasi milenia dan mereka sedang dalam masa yang gencar-gencar untuk membuka usaha seperti café tapi karna kurangnya informasi tentang harga material mereka sendiri harus meluangkan waktu untuk mencari atau pergi ke toko material hanya sekedar mencari tau harga material bangunan.

Dalam era sekarang ini kita semua tentunya semakin di mudahkan dengan teknologi salah satu teknologi yang sering kita pakai untuk aktifitas sehari-hari adalah telpon genggam, telpon genggam yang terus berevolusi dari waktu ke waktu memberikan kita kemudahan untuk berkomunikasi atau berbagi informasi seperti contoh sekarang yang sering kita pakai adalah smartphone, smartphone sendiri memberikan kita kemudahan yang sudah cukup membantu dalam aktifitas sehari-hari oleh karna itu banyak juga pelaku usaha memanfaatkan teknologi ini untuk mengembangkan usaha mereka. Dengan demikian juga pelaku usaha toko material banguanan memiliki kesempatan untuk mengembangkan usaha mereka agar bisa di akses oleh lebih banyak orang dengan memanfaatkan teknologi Smartphone agar supaya informasi harga material bangunan dengan sangat mudah bisa di akses oleh berbagai kalangan masyarakat.

Dengan kemudahan yang sudah di berikan maka di harapkan bisa membantu sebagian masyarakat untuk mengakses juga daftar harga material dengan menggunakan aplikasi yang sudah di sediakan dalam bentuk Android yang tersedia dalam Smartphone.

\section{A. Sistem Informasi}

[6] Sistem Informasi adalah kombinasi dari manusia, fasilitas atau alat teknologi, media, prosedur dan pengendalian yang ditujukan untuk mengatur jaringan komunikasi yang penting, proses transaksi tertentu dan rutin, membantu manajemen dan pemakai intern dan ekstern dan menyediakan dasar untuk pengambilan keputusan yang tepat 


\section{B. Material Bahan Bangunan}

${ }^{[8]}$ Material merupakan komponen yang penting dalam menentukan besarnya biaya suatu proyek, lebih dari separuh biaya proyek diserap oleh material yang digunakan.

Dari defenisi bahan bangunan yang sudah di kemukakan oleh para ahli dapat disimpulkan bahwa bangunan yang indah dan kuat itu bergantung dari jenis bahan yang di gunakan

\section{C. $\quad$ Android}

${ }^{[7]}$ Android Merupakan sistem operasi untuk telpon selular yang berbasis Linux. Android menyediakan platform terbuka bagi para pengembang untuk menciptakan aplikasi mereka sendri untuk digunakan oleh bermacam perantik bergerak. Android umum digunakan di smartphone dan juga tablet PC. Fungsinya sama seperti sistem operasi Symbian di Nokia, iOS di Apple dan BlackBerry OS.

\section{Android Studio}

Android studio adalah IDE (Integrate Development Environment) resmi untuk pengembang aplikasi Android dan bersifat open source atau gratis, peluncuran Android Studio ini diumumkan oleh Google pada 16 mei 2013 pada event Google I/O Conference untuk tahun 2013. Sejak saat itu, Android studio mengantikan Eclipse sebagai IDE resmi untuk mengembangkan aplikasi Android.

\section{E. Aplikasi}

${ }^{[3]}$ Aplikasi adalah suatu sub kelas perangkat lunak computer yang memanfaatkan kemampuan komputer langsung untuk melakukan suatu tugas yang diinginkan penguna. Biasanya dibandingkan dengan perangkat lunak system yang mengintegrasikan berbagai kemampuan komputer, tapi tidak secara langsung menerapkan kemampuan tersebut untuk mengerjakan suatu tugas yang menguntungkan penguna.

\section{F. Perancangan}

${ }^{[4]}$ Perancangan adalah tahapan perancangan (design) memiliki tujuan untuk mendesain sisem baru yang dapat menyelesaikan masalah-masalah yang dihadapi perusahaan yang diperoleh dari pemilihan alternative sistem terbaik.

\section{G. Basis Data}

${ }^{[2]}$ Istilah Database banyak menimbulkan interpretasi yang berbeda. Basis Data adalah sistem berkas terpadu yang dirancang terutama untuk meminimalkan pengulangan data. Kelemahan perancangan system masih didasarkan pada kebutuhan individu penguna, bukan kebutuhan sejumlah penguna dengan kekurangan dalam hal :

1. Kemubaziran data.

2. Keterbatasan Konsistenan dan kurangnya integritas.

3. Kekurangan luwesan.

Sistem pemrosesan database dimaksudkan untuk mengatasi kelemahan-kelemahan yang ada pada sistem pemrosesan berkas. Sistem seperti ini dikenal dengan sebutan Database Management System (DBMS)
H. Java

Java adalah Bahasa pemograman berorientasi objek murni yang dibuat berdasarkan kemampuan-kemampuan terbaik Bahasa pemograman objek sebelumnya (C++,ada,simula). Java diciptakan oleh James Glosing, developer dari Sun Microsistems pada tahun 1991

\section{I. $\quad$ PHP (Personal Home Page)}

PHP adalah Bahasa server-side -scripting yang menyatu dengan HTML untuk membuat halaman web yang dinamis. Karena $P H P$ merupakan server-side-scripting maka sintaks dan perintah-perintah PHP akan diesksekusi diserver kemudian hasilnya akan dikirimkan ke browser dengan format $H T M L$

\section{J. $\quad M y S Q L$}

$M y S Q L$ adalah salah satu jenis database server yang sangat terkenal dan banyak digunakan untuk membangun aplikasi web yang menggunakan database sebagai sumber pengolahan datanya

$M y S Q L$ merupakan database yang pertama kali didukung oleh bahasa pemrograman script untuk internet (PHP dan Perl). MySQL dan PHP dianggap sebagai pasangan software pembangun aplikasi web yang ideal. $M y S Q L$ lebih sering digunakan untuk membangun aplikasi berbasis web, umumnya pengembangan aplikasinya menggunakan bahasa pemrograman script PHP.

\section{II.METODOLOGI PENELITIAN}

\section{A. Data Primer}

Data primer merupakan data utama dalam penelitian ini.Data ini di peroleh dari observasi langsung di lapangan dari lokasi penilitian di beberapa toko material bangunan yang berada di kota Manado Sulawesi Utara.

\section{B. Data Sekunder}

Data sekunder adalah data yang merupakan pendukung dari data utama yang mana data Ini di peroleh dari user, dimana user yang terdaftar memiliki hak untuk memperlengkap data harga bahan material, data dari user kemudian di olah dan di input ke dalam database ketika data tersebut telah mendapatkan Validasi

\section{Tempat Dan Lokasi Penelitian}

Lokasi penelitian ini bertempat di Kota Manado, Ibukota Sulawesi Utara. Dan waktu penelitian ini berlangsung dari Tangal 18 Maret 2018 - 30 maret 2018, dengan mengambil daftar harga bahan material di beberapa toko material di kota manado.

\section{Alat dan Bahan}

Tools yang di gunakan pada penelitian ini dapat di lihat pada tabel I.

\section{E. Prosedur Penelitian}

Tahapan ini merupakan kerangka kerja berupa langkalangka dalam pelaksanaan penelitian. Kerangka kerja yang digunakan menggunakan Metodologi RAD ( Rappid Application Development ). 
TABEL I

ALAT DAN BAHAN PENELITIAN

\begin{tabular}{|c|c|c|c|}
\hline No & $\begin{array}{l}\text { Langkah- } \\
\text { langkah } \\
\text { Aktifitas Riset }\end{array}$ & $\begin{array}{l}\text { Tools yang } \\
\text { Digunakan }\end{array}$ & Ket \\
\hline 1 & $\begin{array}{l}\text { Pengembangan } \\
\text { sistem }\end{array}$ & Laptop & $\begin{array}{l}\text { Spesifikasi: } \\
\text { - HP } \\
\text { (Hewlett- } \\
\text { Pakcard) } \\
\text {-Prosesor } \\
\text { AMD A9- } \\
9420 \\
\text { RADEON R5 } \\
\text {-RAM } 4.00 \\
\text { GB } \\
\text {-OS Windows } \\
1064 \text { bit }\end{array}$ \\
\hline 2 & $\begin{array}{l}\text { Perancangan } \\
\text { antar muka }\end{array}$ & XML & $\begin{array}{l}-\mathrm{XML} \\
\text { Android }\end{array}$ \\
\hline 3 & $\begin{array}{l}\text { Perancangan } \\
\text { logika }\end{array}$ & JAVA & $\begin{array}{l}- \text {-Java } \\
\text { Android }\end{array}$ \\
\hline 4 & IDE & Android Studio & $\begin{array}{l}\text {-Versi } \\
\text { Terbaru }\end{array}$ \\
\hline 5 & Backend & HeidiSql & $\begin{array}{l}\text {-Fitur Item } \\
\text {-Fitur Table } \\
\text {-Fitur } \\
\text { Database } \\
\text {-Fitur } \\
\text { analytics }\end{array}$ \\
\hline
\end{tabular}

\section{Requerements Planning (Perancanaan Persyaratan)}

Fase ini bertujuan mengidentifikasin kebutuhan ,syarat batasan dan objektifitas dari Aplikasi atau sistem yang akan di bangun. Data mengenai kebutuhan sistem yang diperoleh dengan cara terjun langsung ke lapangan memantau dan menganalisis secara saksama dengan menggunakan media pengambilan data daftar harga material bangunan.

\section{Design Workshop (Pemodelan)}

Fase ini adalah fase untuk merancang dan meningkatkan pemahaman terhadap permasalahan yang ada berdasarkan analisis yang telah dilakukan. Fase ini digambarkan dengan deskripsi Business Process

Perancangan Aplikasi android Daftar Harga Material Bangunan di mulai dari mengidentifikasi data internal maupun eksternal yang di butuhkan untuk di gunakan. Untuk mempermudah gambaran dari hubungan sistem dan pengguna maka di gunakan use-case diagram dan Tabel Manipulasi Data (lihat pada gambar 1)..
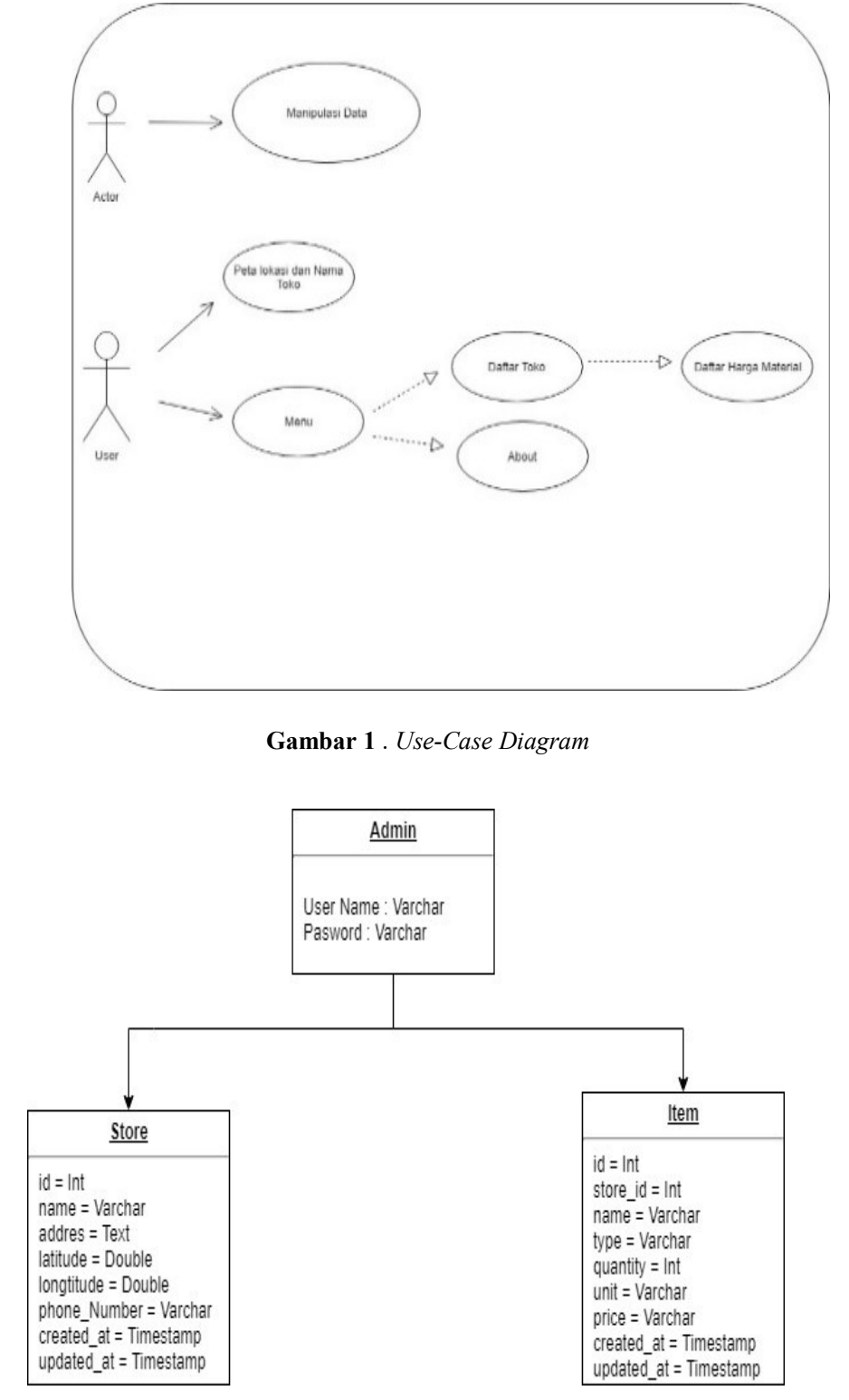

Gambar 2. Class Diagram

3. Structural Model (Pemodelan Struktural)

Pada proses ini akan di jelaskan proses calss diagram yang di gunakan guna untuk memberikan gambaran sistem yang menunjukan hubungan dari kelas-kelas diagram yang terintegrasi (lihat pada gambar 2)

\section{Sequence Diagram}

Pada tahap ini sistem perancangan di buat berdasarkan objek dengan mengunakan sequence diagram. Dimana diagram sequence di gunakan untuk mengambar scenario atau langkahlangkah yang dilakukan sebagai respon dari suatu kejadian yang terjadi dari sistem yang menghasilkan output tertentu. 


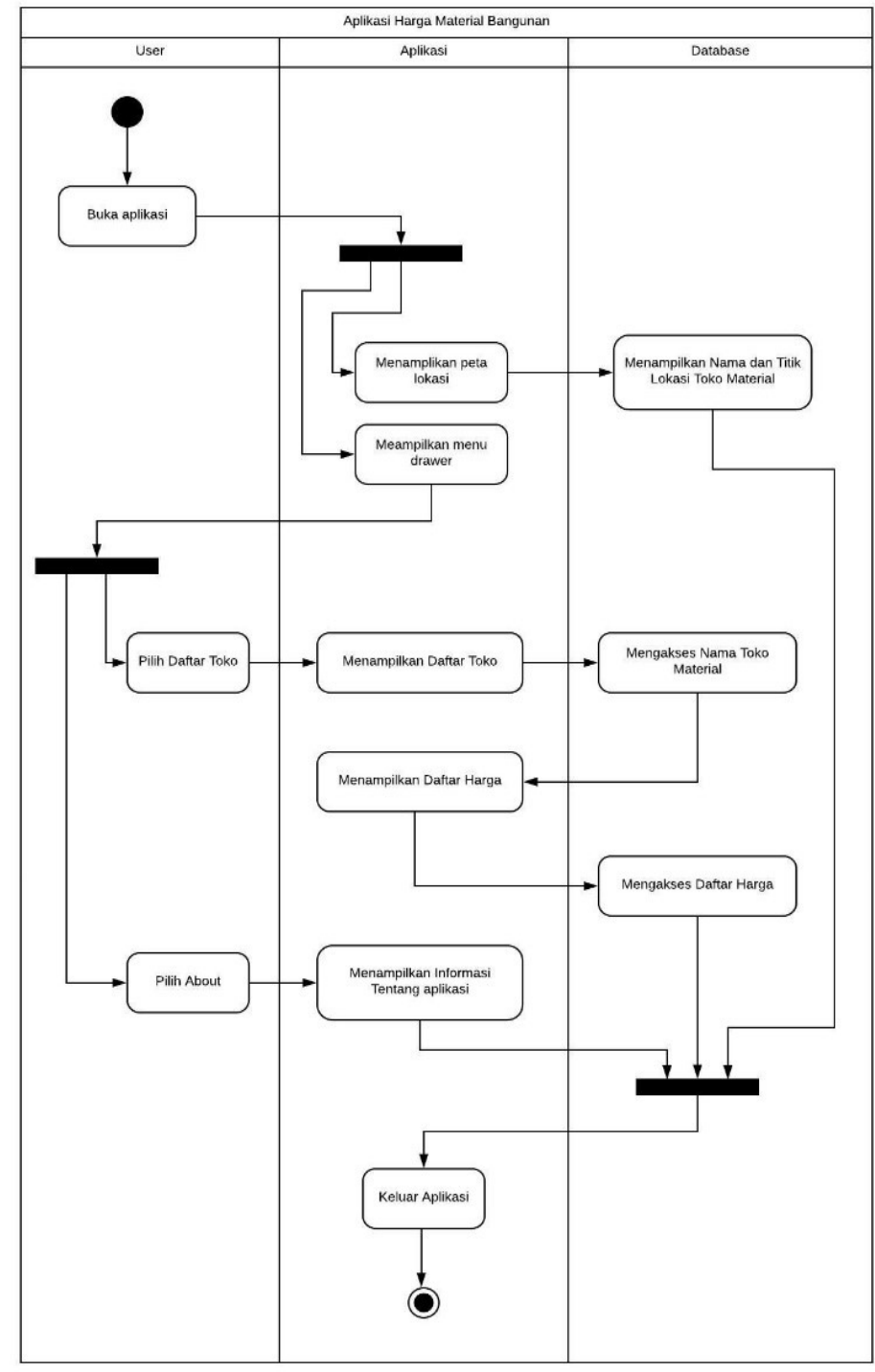

Gambar 3. Activity Diagram

\section{Activity Diagram}

Aktivity Diagram Aplikasi Daftar Harga Material Bangunan menunjukan urutan aplikasi dalam penguna aplikasi, yang di mulai dari user membuka aplikasi pada saat aplikasi di buka akan muncul tampilan awal aplikasi yang menampilkan Maps Kota Manado serta titik lokasi toko material bangunan (Lihat Gambar 3).

\section{Storyboard}

Tabel di bawah ini menunjukan Storyboard dari aplikasi Daftar Harga Material Bangunan Berbasis Android yang memiliki 5 tampilan, tabel storyboard bisa dilihat pada tabel II.
TABEL II

STORYBOARD APLIKASI

\begin{tabular}{|c|c|c|}
\hline SCENE & VISUAL & DESKRIPSI \\
\hline 1 & $\log 0$ & $\begin{array}{l}\text { Tampilan ini, } \\
\text { adalah tampilan } \\
\text { Loading. } \\
\text { Tampilan awal } \\
\text { saat kita masuk } \\
\text { pada Aplikasi } \\
\text { Daftar Harga } \\
\text { Material } \\
\text { Bangunan } \\
\text { Berbasis } \\
\text { Android. }\end{array}$ \\
\hline 2 & EEST & $\begin{array}{l}\text { Halaman } \\
\text { selanjutnya dari } \\
\text { aplikasi ini ialah } \\
\text { menampilkan } \\
\text { peta lokasi kota } \\
\text { Manado serta } \\
\text { menampilkan } \\
\text { titik lokasi toko } \\
\text { material } \\
\text { bangunan yang } \\
\text { ada di kota } \\
\text { Manado }\end{array}$ \\
\hline 3 & 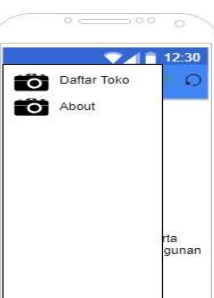 & $\begin{array}{l}\text { Tampilan ini } \\
\text { menampilkan } \\
\text { menu yang ada } \\
\text { pada aplikasi, } \\
\text { menu yang } \\
\text { terdapat pada } \\
\text { aplikasi ini ialah } \\
\text { Daftar Toko dan } \\
\text { Abaout. }\end{array}$ \\
\hline 4 & \begin{tabular}{|l|} 
C Datar Toko \\
Toko Material 1 \\
Toko Material 2 \\
Toko Material 3 \\
Toko Material 4 \\
Toko Material 5 \\
Toko Material 6 \\
\end{tabular} & $\begin{array}{l}\text { Selanjutnya } \\
\text { Setelah Memilih } \\
\text { daftar toko pada } \\
\text { aplikasi maka } \\
\text { akan muncul } \\
\text { nama-nama } \\
\text { toko material } \\
\text { bangunan yang } \\
\text { terdapat pada } \\
\text { menu daftar } \\
\text { toko. }\end{array}$ \\
\hline 5 & 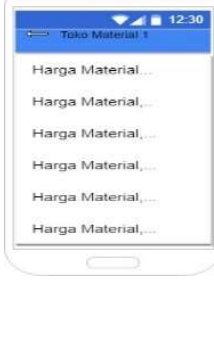 & $\begin{array}{l}\text { Setelah memilih } \\
\text { sala satu toko } \\
\text { material maka } \\
\text { akan muncul } \\
\text { tampilan berupa } \\
\text { daftar harga } \\
\text { material di sala } \\
\text { satu toko } \\
\text { material yang } \\
\text { sudah di pilih. }\end{array}$ \\
\hline
\end{tabular}




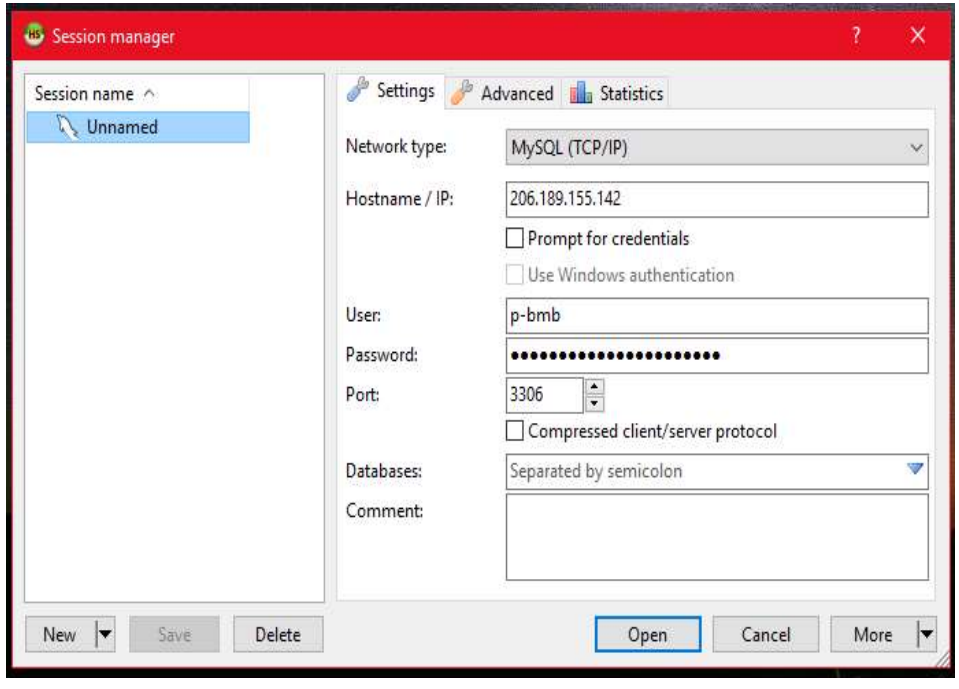

Gambar 4. Log-in HeidiSQL

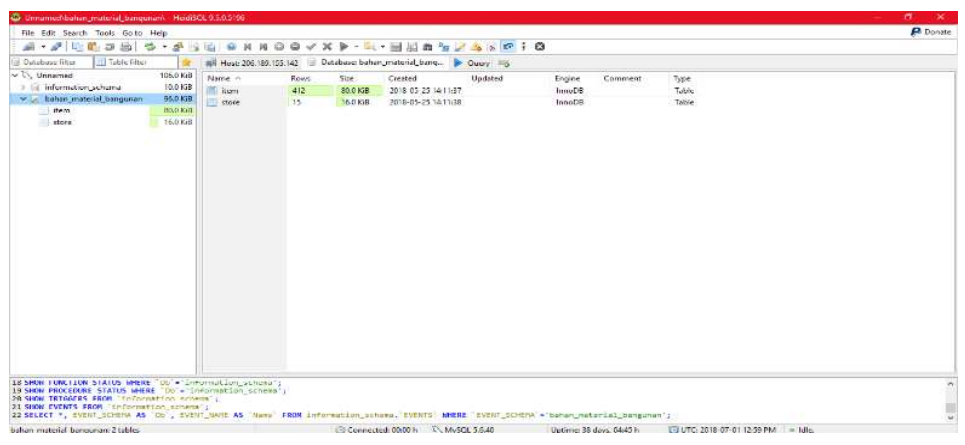

Gambar 5. Database HeidiSQL

\section{HASIL DAN PEMBAHASAN}

Setelah melakukan semua tahapan dari metode Rapid Applikation Development yang dikemukakan pada bab sebelumnya, dilanjutkan dengan hasil penjelasan dari perancangan yang dilakukan berdasarkan tujuan awal dari penelitian ini yaitu Aplikasi Informasi Daftar Harga Material Berbasis Android di Kota Manado.

\section{A. HeidiSOL}

Aplikasi Daftar Harga Material ini memanfaatkan HeidiSQL sebagai backend dimana fitur yang digunakan antara lain:

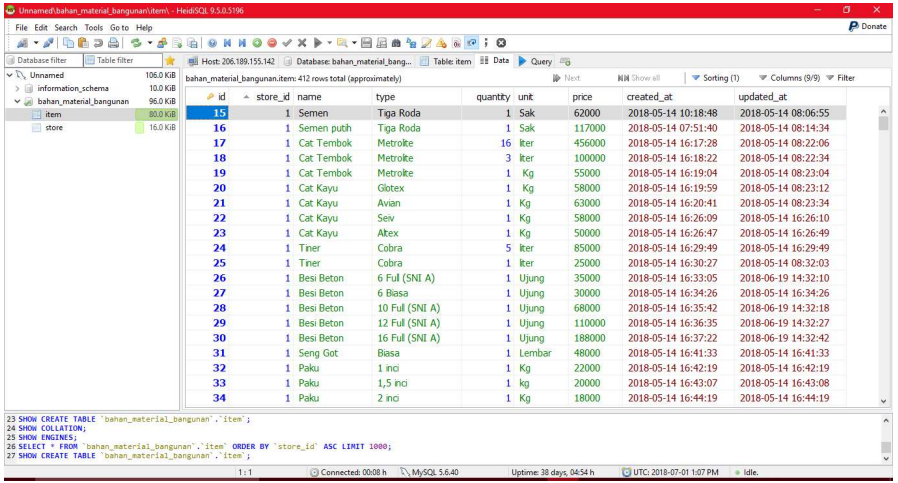

Gambar 6. Database Item

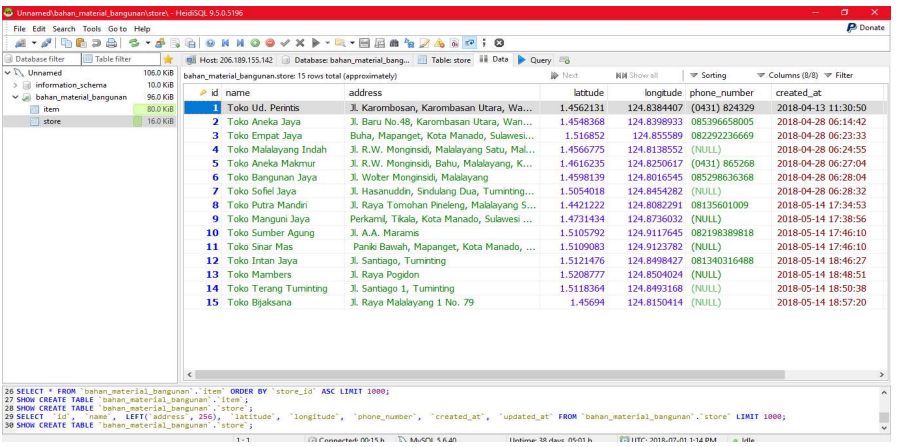

Gambar 7. Database Store

\section{Log-in HeidiSQL}

Pada Aplikasi Daftar Harga Material ini mengunakan HeidiSQL untuk melakukan olah data, dimana hanya admin yang memiliki akses untuk melakukan olah data di dalamnya dengan melakukan Login (Gambar 4).

\section{Database HeidiSQL}

Aplikasi Dafar Harga Material ini mengunakan Database HeidiSQL untuk mengolah dan menyimpan data. HeidiSQL ini di pilih karna proses penyimpanan data yang mudah di gunakan oleh admin sendiri (Gambar 5).

\section{Database Item}

Tampilan gambar di atas merupakan menu item yang ada pada Aplikasi Daftar Harga Material dimana fitur tersebut berfungsi untuk mengolah data daftar harga material (Gambar $6)$.

\section{Database Store}

Fitur terakhir dari aplikasi ini adalah daftar nama toko material yang ada di kota Manado dimana terdapat alamat toko serta titik lokasi toko yang di tampilkan pada menu maps pada aplikasi Daftar Harga Material di Kota Manado (Gambar 7). 


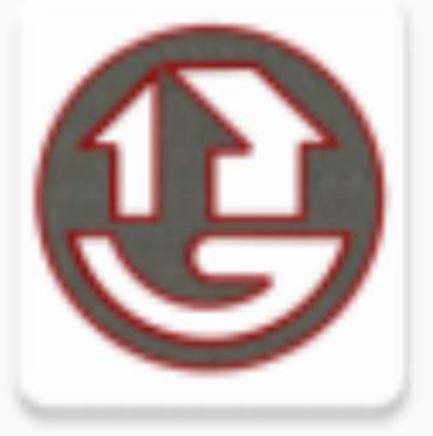

Gambar 8. Logo Aplikasi

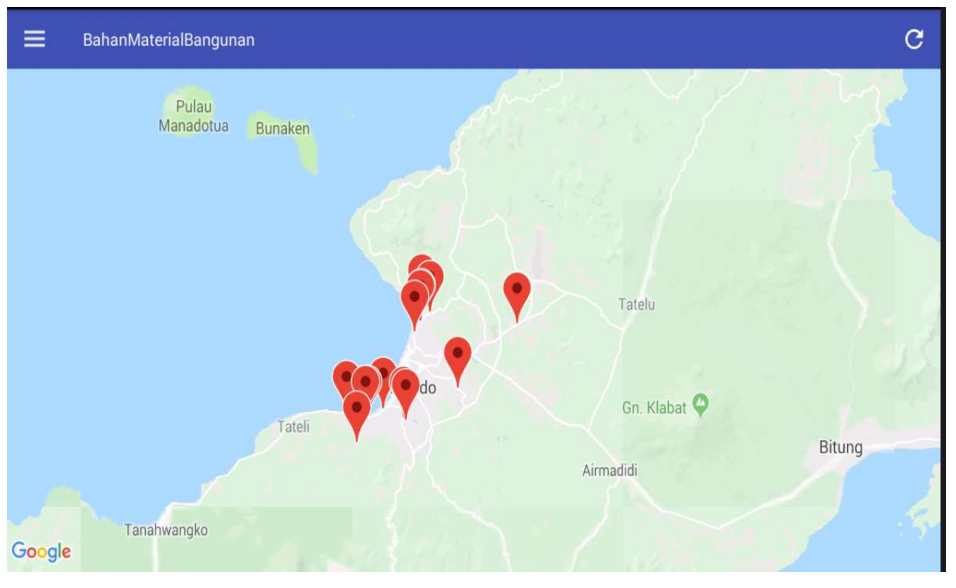

Gambar 9. Maps Lokasi Toko

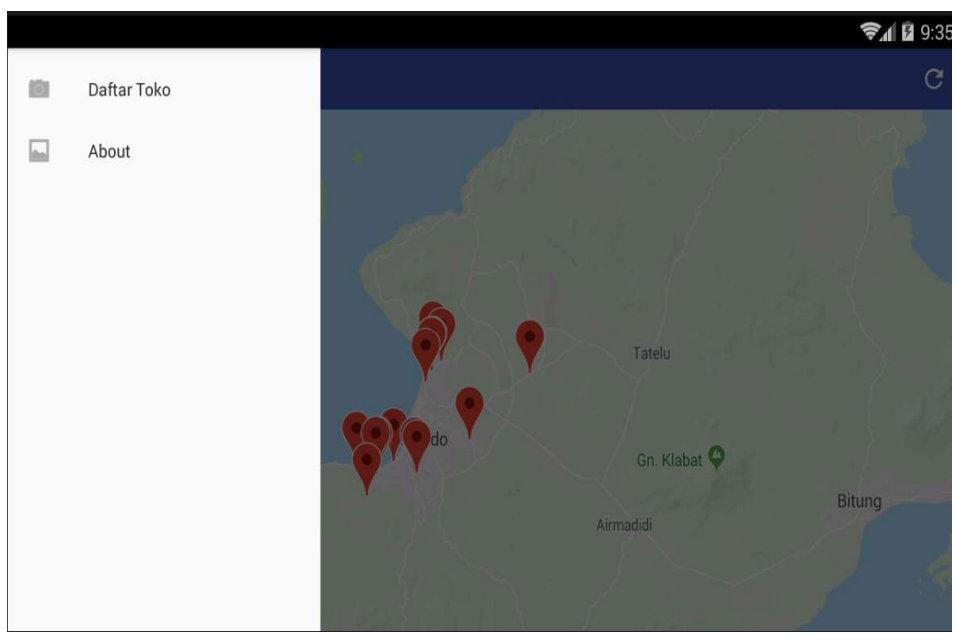

Gambar 10. Menu Aplikasi

B. Tampilan Aplikasi

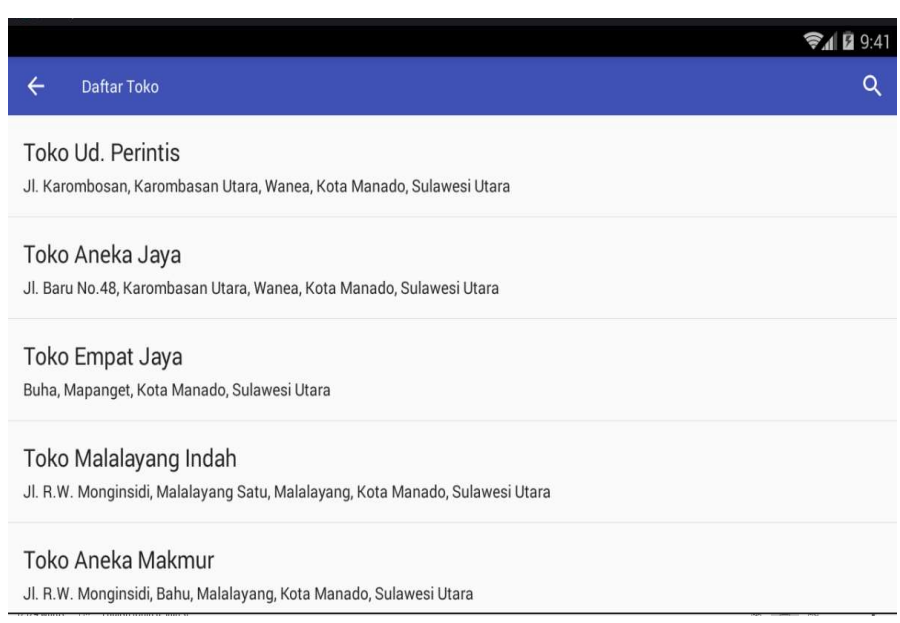

Gambar 11. Tampilan Nama Toko

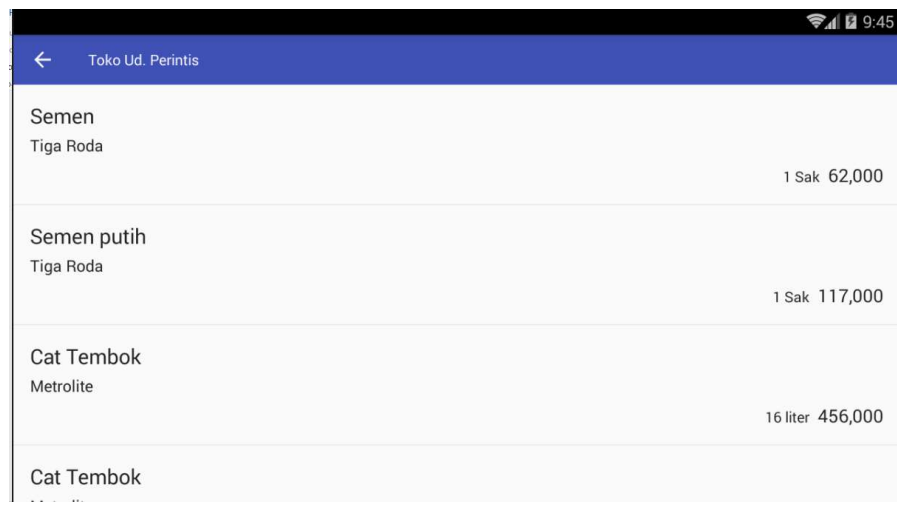

Gambar 12. Daftar Harga Material

1). Tampilan Masuk Aplikasi

Tampilan Logo merupakan tampilan yang akan muncul pertama kali. Dimana proses masuk tidak mengunakan login karna aplikasi ini sendiri hanya menyediakan informasi harga material yang bisa di akses oleh semua orang tanpa melakukan login untuk masuk ke dalam aplikasi (Gambar 8).

\section{2). Tampilan Lokasi Toko}

Tampilan berikut yang akan muncul adalah titik lokasi toko material yang ada di kota manado, dimana penguna aplikasi sudah bisa melihat titik lokasi masing-masing toko yang ada di kota manado (Gambar 9).

\section{3). Tampilan Menu Aplikasi}

Tampilan menu yang ada pada aplikasi dimana terdapat dua pilihan menu yang bisa di akses oleh penguna aplikasi.

Berikut adalah navigasi dari tiap menu yang terdapat pada (Gambar 10):

- Menu Daftar Toko : Menampilkan nama-nama toko material

- Menu About : Menampilkan informasi tetang aplikasi 
TABEL III

RENCANA PENGUJIAN APLIKASI

\begin{tabular}{ccc}
\hline Item Uji & Butir Uji & $\begin{array}{c}\text { Jenis } \\
\text { Pengujian }\end{array}$ \\
\hline Logo & User session proses & Black Box \\
Maps & Tampilan Lokasi Toko & Black Box \\
Menu & Daftar Toko Dan & Black Box \\
& About & \\
\hline \multicolumn{3}{c}{ TABEL IV } \\
\hline \multicolumn{2}{c}{ REKAP PENGUJIAN LOGO } \\
\hline Unjuk kerja & Keterangan \\
\hline
\end{tabular}

\section{4). Tampilan Daftar Toko/Nama Toko Material}

Tampilan ini menampilkan nama-nama toko material yang ada di kota Manado dimana penguna aplikasi bisa memilih toko yang akan di lihat daftar harga bahan material yang terdapat dalam masing-masing toko yang tersedia di aplikasi (Gambar 11).

\section{5). Tampilan Daftar Harga Material}

Tampilan terakhir ini menampilkan daftar harga material yang ada di toko material saat penguna aplikasi memilih toko yang akan di lihat daftar harga bahan material. Penguna aplikasi juga di mudahkan untuk memilih dan melihat daftar harga material tanpa harus pergi ke toko material untuk mencari tau harga bahan material yang akan di beli (Gambar 12).

\section{Pengujian Aplikasi}

Pengujian aplikasi merupakan hal terpenting yang dilakukan untuk menemukan kukurangan atau kesalahan pada perangkat lunak yang di uji,.Pengujian bermaksut mengetahui perangkat lunak yang dibuat sudah memenuhi kriteria yang sesuai dengan tujuan perancangan perangkat lunak. Pengujian ini mengunakan Black Box

\section{1). Pegujian Black Box}

Penguhjian Black Box di lakukan dimana untuk mengetahui apakah fungsi dari aplikasi sudah berjalan dengan baik.

- Kategori Pengujian dalam Keberhasilan

Dalam pengujian perangkat lunak haru ditetapkan kategori keberhasilan dalam setiap kasus uji yang dilakukan, berikut ini dikelompokk

- Berhasil

Untuk katagori berhasil dimana aplikasi sudah berjalan sebagaimana yang di inginkan.

\section{- Gagal}

Untuk kategori ini dimana ada kekurangan atau ada bagian yang tidak berfungsi pada aplikasi.

an dua kategori keberhasilan sebagai berikut :
TABLE V

REKAP PENGUJIAN LOKASI TOKO

\begin{tabular}{cc}
\hline Unjuk Kerja & Keterangan \\
\hline Menampilkan Maps & Berhasil \\
Menampilkan Titik \\
Lokasi Toko \\
Menampilkan Nama \\
Toko & Berhasil \\
\hline
\end{tabular}

TABEL VI REKAP PENGUJIAN MENU DRAWER

\begin{tabular}{cc}
\hline Unjuk Kerja & Keterangan \\
\hline Menampilkan Menu & Berhasil \\
Drawer & Berhasil \\
Menampilkan Daftar toko & Berhasil \\
Menampilkan About & \\
\hline
\end{tabular}

TABEL VII

REKAP PENGUJIAN DAFTAR TOKO

\begin{tabular}{cc}
\hline Unjuk Kerja & Keterangan \\
\hline Menampilkan Nama & Berhasil \\
Toko & \\
Menampilkan Daftar & Berhasil \\
Harga Material & \\
\hline
\end{tabular}

\section{2). Rencana Pengujian}

Pengujian Aplikasi Daftar harga material di lakukan dalam bebrapa tipe ponsel untuk mengetahui apakah aplikasi ini bisa di akses untuk semua tipe android.

\section{Rekap Pengujian}

Rekap pengujian ini terdiri dari beberapa tahap uji aplikasi yan di mulai dari tampilan logo yang terdapat pada Tabel IV, selanjutnya rekap pengujian lokasi toko terdapat pada table V, rekap pengujian menu drawer terdapat pada table VI, dan yang terakhir rekap pengujian daftar toko terdapat pada table VII.

\section{Hasil Pengujian}

Berdasarkan data rekap pengujian maka aplikasi daftar harga material bangunan sudah memenuhi kriteria dan sudah bisa untuk di akses. Untuk itu pengujian selanjutnya di lakukan di ponsel android, ponsel android yang telah di uji adalah sebagai berikut:

1. Samsung Galaxy Mega, Layar 6.3 “,OS Android API 17 (Jelly Bean) 
2. Samsung Galaxy S5, Layar 5,2", OS Android API 23 (Marshmallow)

3. Xiaomi Redmi Note 3, Layar 5,3", Android API 22 Lollipop

\section{PENUTUP}

A. Kesimpulan

Dengan adanya pengujian pada tahap akhir didapatkan kesimpulan sebagai berikut :

1) Telah berhasil di kembangkan sebuah aplikasi daftar harga material berbasis android di kota Manado.

2) Aplikasi Daftar Harga Material ini dikembangkan dengan menggunakan metode $R A D$ ( Rappid Application Development)

3) Hasil dari penelitian ini berupa aplikasi daftar harga material yang memudakan penguna untuk sekedar mencari tau informasi harga material yang ada di kota Manado.

4) Dari hasil penelitian ini dapat di ambil kesimpulan bahwa harga semen di Toko UD Perintis terbilang sedikit lebih murah di banding toko lain tapi bukan bearti sudah termasuk paling murah di wilayah kota Manado.

B. Saran

Berdasarkan hasil penelitian dan kesimpulan mengenai Aplikasi Daftar harga material bangunan maka di ajukan saran sebagai berikut:

1) Untuk pengembangan aplikasi selanjutnya kiranya bisa di tambahkan fitur transaksi jual beli.

2) Data toko bisa di tambah seiring dengan permintaan konsumen

3) Karena Aplikasi bersifat umum kiranya bisa memudahkan semua orang untuk mengakses informasi lebih bagus lagi.

\section{DAFTAR PUSTAKA}

[1] Agus Mulyanto. 2009. Sistem Informasi Konsep dan Aplikasi. Pustaka Pelajar. Yogyakarta

[2] Anjar Setianingsih. 2013. "Sistem informasi pembelian dan penjualan bahan bangunan pada toko cipta jaya punung"

[3] Barry Pratama[1]"Pegertian Aplikasi"

[4] Bin Ladjamudin(2005:39) "Pengertian Perancangan"

[5] Hermawan S, Stephanus. 2011."Mudah Membuat Aplikasi Android.Yogyakarta

[6] Nash, John F. 1995. Pengertian Sistem Informasi. Jakarta : Informatika

[7] Nazarudin Safaat Harahap. 2012. Pemograman Aplikasi Mobile Smartphone dan Tablet PC Berbasis Android. Informatika. Bandung.

[8] Nugraha, 1985. Analisis pengunaan aplikasi software optimasi waste besi pada pekerjaan struktur beton bertulang proyek xyz
Sekilas dari penulis dengan nama lengkap Rian Tarsis

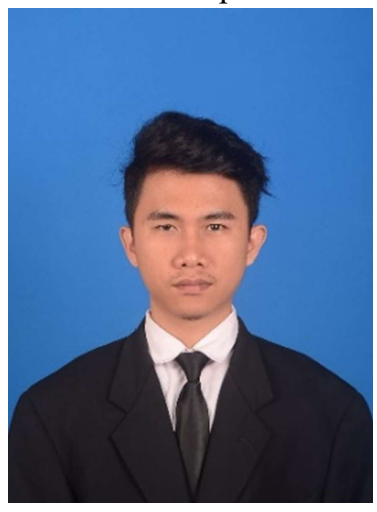

Tjioetama, lahir di kota Manado, Provinsi Sulawesi Utara. Anak Tunggal. Dengan pendidikan Sekolah Dasar SD Katolik 09 Hati Kudus Manado. Kemudian Melanjutkan ke Sekolah Menengah Pertama Negeri SMP N 3 Manado. Kemudian melanjutkan ke Sekolah Menengah SMK N 3 Manado.

Setelah lulus tahun 2011 melanjutkan ke Perguruan Tinggi di Universitas Sam Ratulangi Manado dengan mengambil Jurusan Teknik Informatika. Pada tahun 2018 bulan Januari, penulis membuat Skripsi demi memenuhi syarat Sarjana(S1) dengan penelitian berjudul Aplikasi Informasi Daftar Harga Material Bangunan Berbasis Android oleh dua dosen pembimbing yaitu Sherwin R.U.A. Sompie, ST., MT

Dan Xaverius B. N. Najoan, ST., MT

sehingga pada tanggal 16 Agustus 2018 penulis resmi lulus di Teknik Informatika Universitas Sam Ratulangi Manado dan menyandang gelar Sarjana Komputer dengan predikat Sangat memuaskan 